\title{
MEDALLISTA 2019, RESPONDE Y AGRADECE
}

\author{
Marcos García de la Huerta
}

$\widehat{R A}$ Señor Rector, Señor Prorector, señores Vicerrectores; Decanos y miembros del Senado Universitario; Autoridades Académicas; representantes de la Corporación Rector Juvenal Hernández; miembros del Instituto de Chile, queridos familiares, amigos y amigas.

Es un gran honor recibir la medalla Rector Juvenal Hernández, y un agrado expresar mi gratitud al jurado que me concedió este prestigioso premio; estuvo presidido por el rector Ennio Vivaldi e integrado por el prorector Rafael Epstein, la vicerrectora académica, Rosa Devés, la representante de la Corporación Rector Juvenal Hernández, Emma Salas, y los académicos Luis Merino y Luis Ciocca, que obtuvieron esta misma distinción el año pasado. A todos les reitero mis agradecimientos.

Ha sido una feliz coincidencia el haber sido precedido en este premio en la versión Humanidades por un académico tan destacado como Luis Merino. La presentación que ha hecho recién muestra la prolijidad y celo con que acomete las tareas que se propone; podría haber tomado un par de artículos o quizá un libro, y de seguro habría hecho una excelente exposición, pero prefirió tomarse el trabajo de leer seis libros, y lo hizo atentamente, identificando tres temáticas relevantes ¿Cómo llamar a eso? ¿Gusto por el trabajo bien hecho? ¿Excelencia? ¿Nobleza? Como sea, el caso es que ha puesto la vara muy alta para lo que venga el año próximo, cuando sea yo quien presente al medallista de 2020 .

Permítanme destacar un par de ejemplos de esta lectura atenta y perceptiva. Luis destaca, por ejemplo, a propósito de mi formación en economía, la teoría monetaria como materia de mi incumbencia. En efecto, llegué a dictar algunos cursos en ese ramo en la Escuela de Negocios de la Universidad Católica de Valparaíso. Él agrega el Derecho del trabajo entre los cursos del plan de estudios de la Escuela de Economía, donde estudié, y recuerda seguidamente, el título de mi tesis de licenciatura: Los factores políticos y sociales de la inflación chilena (1960). La mención de este título, junto a lo anterior, relativo a teoría monetaria, no es casual y sugiere claramente, que en esa fecha tan temprana -1960-, yo expresaba dudas sobre la pertinencia del monetarismo-léase teoría neoliberal- en la comprensión del fenómeno inflacionario chileno.

Otra de las temáticas que destacó Luis es la cuestión de los cruces, es decir, la idea que la filosofía no se limita a comentar a los autores del pasado o del presente, sino que su interés se extiende a todo el espectro de los saberes y prácticas humanas, en tanto remiten a la pregunta por el sentido. Eso implica asumir múltiples competencias: como Ética, en relación con la pregunta por la vida buena; como Filosofía jurídica, en relación con la cuestión de las formas de legitimación del poder y los fundamentos del derecho; como Filosofía de la ciencia, inquiere acerca de las condiciones y posibilidades del conocimiento teórico; como Filosofía de la técnica, analiza los efectos de la extensión 
de la racionalidad instrumental sobre el mundo humano; como Estética interroga la cuestión del gusto y el significado de la obra de arte; en relación con la sicología y la siquiatría, incursiona en los enigmas insondables del alma humana; $y$, por último, pero no menos importante, como Filosofía política, indaga en las condiciones del bien de la ciudad y el significado del acontecimiento.

Esta vastedad de intereses no significa que ella invada el campo de las especialidades; cruce significa empalme, intersección, no intromisión; se puede expresar también como una paradoja: la filosofía se ocupa de todo, en cuanto interroga por el sentido, o bien: la filosofía no tiene objeto: lo que la define es un modo de pensar más que un objeto de estudio determinado.

Acerca de este mismo acto cabe preguntar por su significado, porque no es evidente por sí mismo y necesita del lenguaje para hacerlo explícito; solo en las acciones instrumentales las palabras están de sobra, pues restan eficacia a la acción. Los actos, por lo demás, también sirven a la comunicación, no solo se comunica con palabras y a veces la comunicación comienza con los actos. Pero, vamos al grano: ¿Qué significa este premio? Desde luego, lo otorga un jurado integrado solo por académicos: es un reconocimiento que le hacen a uno sus colegas, sus iguales: esto tiene un valor muy especial, porque lo que se pone en la balanza es la trayectoria y el aporte a la Universidad. Y esta, a su vez, se afirma a sí misma y se identifica como espacio inquisitivo y crítico dentro del espacio público, reconociendo a quienes encarnan los valores que ella misma aspira representar: el pluralismo, la tolerancia, el secularismo, el espíritu de la razón ilustrada. Esta es, por así decirlo, la otra cara de la Medalla, su anverso: su realidad institucional y pública.

Por otra parte, el otorgamiento de este premio en las dos versiones -ciencias y humanidades-, se celebra cada año en un evento como este, y es el otro aspecto significativo de este acto: su repetición. Pero se repite algo que cada vez es distinto, en la medida que los actores que intervienen hablan con voz propia. El galardonado del año anterior hace de pivote entre la celebración anterior y la actual. Esta estructura dual hace posible que lo repetido sea reasumido y retomado cada vez de otra manera, es decir, que algo que ya existía, comience a ser de nuevo de otro modo. En el orden de la naturaleza, la repetición hace posible la ley que registra la regularidad; la reiteración en este caso, es estereotipada, mecánica o casi mecánica, aunque no del todo desnuda de modificaciones y variantes, siempre dentro de un mismo canon. En cambio, cuando lo mismo se reitera cada vez de modo diferente, la repetición adquiere un sentido identificador: se reitera un ritual que al mismo tiempo es un acto singular e irrepetible.

¿Qué significa, entonces, repetición? Lo que Freud llamó “compulsión de repetición", refiriéndose a los sueños que se reiteran, tiene un significado por completo diferente: responderían dichos sueños a una pulsión o tendencia contrapuesta al principio del placer. Los sueños que vuelven, según esa visión, contendrían un mensaje cifrado, que responde al insistente retorno de un conflicto no resuelto y frente al cual el sujeto, desde lo más recóndito de sí, solo puede reaccionar repitiendo. La reiteración adquiere el carácter de un confinamiento involutivo, que no conduce a algo distinto, ni promisorio ni creador. Las figuras mitológicas de Prometeo encadenado y de Sísifo, condenado a 
un trabajo inútil y sin esperanza, pueden ilustrar esta reclusión en la monotonía de lo mismo, siempre igual. En cambio, se supone que los ritos mágicos ganan en eficacia con la reiteración.

Sin embargo, aun restando toda la magia que pueda haber en la repetición, subsiste un remanente enigmático. Continuar haciendo lo que siempre se hizo, ante el temor de que nada podrá seguir siendo igual, sobre todo si las cosas no pintan para mejor ¿No tiene el mismo efecto reparador y autoafirmador que el imaginario mítico atribuye al mantra?

Lo que permite, en todo caso, que la repetición sea renovadora, es el relevo y su carácter verbal. Las palabras no están de sobra: lo decíamos al comienzo, porque poseen un poder liberador: permiten que la reiteración deje intacta la singularidad de cada acto. Así debe ocurrir de nuevo en un acto como este, que celebremos con similar emoción y alegría el año próximo.

Muchísimas gracias

Santiago, 11 de diciembre de 2019 